\title{
Teachers' Beliefs about Poverty and the Impact on Learning Disabilities Identification in a Poor, Rural School District
}

\author{
Renee Chandler \\ University of Wisconsin-Stout
}

\begin{abstract}
This qualitative case study examined a rural school district where many of the students live in poverty. The purpose of the study was to develop a deeper understanding of the learning disability $(L D)$ identification process as implemented in a high-poverty rural setting. Analysis of the data revealed the prevalence of some stereotypical beliefs regarding poverty. In addition, the findings revealed use of a traditional, Intelligence Quotient (IQ)Achievement discrepancy model rather than Response to Intervention (RTI). Furthermore, participants conveyed that their deliberations do not typically include the legally required consideration that other factors (such as poverty) may be the primary reason that the student is struggling. Recommendations include providing educational activities to challenge stereotypical beliefs about people living in poverty, considering socioeconomic reform in discussions about school improvement, supporting teachers in their efforts to meet the needs of all students in their classrooms, and implementing assessment methods designed to help students receive the assistance needed as early as possible.
\end{abstract}

Key words: rural education, rural schools, high-poverty schools, learning disability

Socioeconomic status serves as the strongest single indicator of students' educational outcomes. Based on a comparison and analysis of test scores, generally children attending high-poverty schools perform at much lower levels in reading and mathematics than their peers who attend low-poverty schools (U.S. Department of Education, 2007). Rural children are more likely to be poor than either nonrural children or children in the United States overall (O'Hare, 2009). In addition, economic development in rural areas is hindered by many elements: low population, lack of infrastructure, dependence upon one employment sector, fewer resources, and lower levels of educational advancement (Jensen, 2006).

This qualitative case study examined one specific rural school district where many of the students live in poverty. The purpose of the study was to develop a deeper understanding of the learning disability (LD) identification process as implemented in a highpoverty rural setting. In working toward this purpose, the researcher explored these questions: What do teachers in a poor rural school district believe about poverty? How do these assumptions impact teachers' decisions on LD eligibility? The research presented in this paper has significance because of its rural context, because it is a qualitative study in a field traditionally dominated by quantitative research, and because it adds to the literature addressing a topic that is highly relevant due to the current implementation of the 2004 revision of the Individual with Disabilities Education Act (IDEA) that introduces new assessment strategies for determining LD eligibility.

The definition of LD has been a controversial topic since the late 1960s (Bateman, 2005). There is significant evidence that the lack of a consistently applied definition has led to misidentification of LD in the U.S. (Dombrowski, Kamphaus \& Reynolds, 2004). Findings of one study indicated only 39 percent of students with the LD label actually qualified for services based on the official definition and criteria for eligibility (Bocian, Beebe, McMillan, \& Gresham, 1999).

Lack of consistency in how learning disabilities are defined is evident. For example, a student may qualify for services because of a learning disability in one state but not in another, Weintraub, 2005).

While the overall incidence rate of students receiving disabilities services is consistent across states, there are apparent differences in how diagnostic criteria or practices are used within each state to determine who is or is not learning disabled (Weintraub, 2005). In other words, the same percentage of students are identified as having a need for special education, but states differ in the labels they assign students.

Given the definition provided in IDEA 2004, the federal government charges schools with the responsibility of deciding which children qualify for 
services under the category of Specific Learning Disability. Traditionally, schools have used an IQAchievement discrepancy model which entails determining the child's intelligence using an individually-administered IQ test. The IQ test supposedly provides an estimate of the child's potential for learning. Special education teachers or school psychologists also administer an achievement test to determine how much the child has actually learned. Using the IQ-Achievement discrepancy model, the two scores are compared and if there is a significant discrepancy between the child's IQ (innate ability) and achievement (actual performance on academic tests), the child can be labeled as having a Learning Disability (LD) (Fuchs \& Fuchs, 2006).

There are several criticisms of this particular model. The tests used to measure IQ and achievement only provide a limited amount of information about how a child actually performs in the classroom (Lerner \& Johns, 2009). In addition, the assessments used do not always discriminate between actual learning disabilities and the results of inadequate teaching. Another criticism of the discrepancy model is that students can be misidentified due to teacher or testing bias.

Perhaps the most problematic issue with the IQAchievement discrepancy model is that it is a "wait to fail" approach. Statistically speaking, most children with LD are not identified until age nine (Lerner \& Johns, 2009). It typically takes a number of years before the discrepancy between a child's achievement and IQ is severe enough to qualify for services. While educators are waiting for the student's achievement to drop far enough to meet the criteria for a severe discrepancy valuable learning opportunities for more intense instruction are lost. Hence, the commonly accepted premise that the IQAchievement discrepancy model is a "wait to fail" approach (Turnbull, Turnbull, \& Wehmeyer, 2007).

In the most recent revision of special education law (IDEA 2004), states are granted the option of using a Response to Intervention (RTI) method of identifying students with LD in lieu of the traditional discrepancy model. The intent behind RTI is to provide struggling students with appropriate interventions before they experience repeated academic failure (Turnbull, Turnbull, \& Wehmeyer, 2007). Although the specifics of implementation are decided upon by individual school districts, RTI is based on the premise that all students are provided with "generally effective" instruction by their classroom teacher and that progress is monitored on a consistent basis (Fuchs et al., 2003). An RTI model also includes the principle that any student who does not respond to typical instruction has an opportunity for more explicit, intensive, and/or supportive instruction (Torgesen, 2002).

Potential benefits of the RTI approach include research-based instructional practices for all students and early intervention (Fuchs et. al., 2003). Instead of "waiting to fail," students begin receiving intensive instruction at the earliest sign of trouble. Students whose learning needs can be remediated through more systematic instruction do not require placement in special education programs. Students who do not meet the severe discrepancy criteria are still having their academic needs met. An IQ test, which does not provide useful data for instructional planning, is no longer a part of the eligibility process (Lyon et al., 2001).

There is also evidence that the "exclusionary clauses" of the LD definition (i.e., environmental, cultural, or economic disadvantage) are often ignored (Fletcher \& Navarrete, 2003). Harris, Gray, Davis, Zaremba, \& Argulewicz (1997) found that less than half the school psychologists surveyed considered exclusionary criteria when making a diagnosis of LD and 37 percent admitted ignoring or trying to get around the exclusionary clauses. There is evidence to suggest that these practices serve to provide struggling students with services, even if the diagnosis is incorrect (Shepard, 1983).

The lack of consideration of exclusionary clauses is particularly relevant in the context of a highpoverty rural school. Rural poverty, in particular, has been largely ignored in the scholarly literature as well as in the popular media. Although more than nine million impoverished people live in rural America, we hear relatively little about rural poverty (Books, 1997). Data reveal the assumption that poverty is an urban problem is misguided. In 2007, 22 percent of children in rural areas were poor compared to only 17 percent in urban areas (O'Hare, 2009). In addition, rural children are more likely to be living in deep poverty, with family incomes less than 50 percent of the poverty threshold (O'Hare, 2009).

Perceptions about the rural poor are also significantly different from perceptions of the urban poor. According to Books (1997),

Popular mythology gives us a picture of the rural poor as self-sufficient farm families content with the pleasures of the simple (and simple-minded) life. Seen apart from this "distorting glass," however, rural poverty would force a closer look at some of the exploitation and injustice that structures United States society and affects its educational practice profoundly. (p. 74)

Because we view the rural poor through a "distorting glass" and because the rural poor are sparsely distributed over large areas, they are easier to ignore. There is a lack of literature specifically 
addressing high-poverty rural schools even although rural children are more likely to be poor than either non-rural children or children in the United States overall (O’Hare, 2009).

\section{Method}

The research methodology for this study was designed using a qualitative case study framework. The methods included semi-structured interviews of teachers, detailed observations of the setting, and a review of online documents to secure data about the school district and the community. This approach allowed the researcher to examine the experiences of the teachers from their own perspectives within a very specific context.

True to the qualitative paradigm, this study presents a rich description of the teachers' stories told from their frames of reference. The researcher selected a sample of one school district with 11 participants within that district in order to develop a richer, cultural description of the context. Gilligan (pseudonym) was selected for the study because it had high numbers of students receiving free and reduced lunch and it was located in a rural setting. The participants were volunteers from the larger population who were recruited via e-mail and a snowballing technique whereby teachers who knew the researcher professionally encouraged their colleagues to participate in the study.

\section{Context}

Gilligan is a small rural town with a total population of 1,410 . The houses are mostly singlefamily dwellings built in 1939 or earlier. The median value for a house in Gilligan is less than half the average home price for the state. In 2007, the median household income in Gilligan was \$31,330 compared to a state average of $\$ 50,578$. Approximately half of Gilligan's students live in the residential area within the village limits with the other half living in the surrounding rural countryside. The country homes are scattered randomly among the gently rolling hills, swamps, and forestland that encircle Gilligan.

Although the countryside is beautiful, many of the homes are rundown farmhouses or trailer houses with inadequate plumbing and insulation.

Gilligan Elementary School and Gilligan Middle/High School are located on the same campus on the west end of town. There are 337 students enrolled in Gilligan Elementary School, 111 students at the middle school, and 160 at the high school. The school buildings are outside the town of Gilligan along the highway which means that both "town" students and "country" students are transported by bus each day. The land immediately surrounding the school grounds is open field with a few scattered clumps of trees. The school facilities appear to be more than adequate for their purpose with the high school boasting an indoor swimming pool and the elementary school is surrounded by the usual collection of playground equipment. Outward appearances of the schools alone would not indicate that this is a high-poverty school district.

Semi-structured interviews were conducted with 11 teachers from the elementary, middle, and high school settings. Potential research participants were contacted by e-mail. Additional participants were recruited using a snowballing technique, including an informational statement the researcher made at a staff meeting. Of the 11 teachers interviewed for this study, five were general education teachers and six were special education teachers. Of this sample, seven were elementary school teachers and four were secondary (middle school/high school) teachers. Nine interviewees were female and two were male. The ages of the participants ranged from mid-20s to late $50 \mathrm{~s}$, with years of teaching experience ranging from one to 28. It is important to note that ten of the 11 participants self-identified their socioeconomic background as middle class, with the final participant describing her socioeconomic background as both poverty and middle class. It is interesting to note that only three of the 11 teachers reported their current residence as Gilligan. Four of the 11 teachers had not taught anywhere other than Gilligan, and only two of the 11 participants had taught in urban settings. These factors may impact their impressions and beliefs regarding the situation at Gilligan.

I used a semi-structured interview format, working from a set of open-ended questionsbut allowing the conversations to go where the participants led. The interview protocol included questions about teachers' background, their school and the socio-economic background of students, challenges and rewards of their position, special needs referral processes and in-class interventions. Sometimes the questions led to other topics that the participants felt were relevant to their experience. Most interviews were concluded within 45 minutes, although one interview was significantly longer at 72 minutes. Participants were interviewed at times and places identified as convenient by each individual.

Interviews were transcribed and then analyzed using a combination of qualitative software (NVivo), researcher coding, and peer review. Participants were given the opportunity to review their transcripts for accuracy. Observations of the setting, the behavior of the participants, and field notes related to other interactions that the researcher had while 
visiting the schools were also made throughout this process and recorded in field notes.

\section{Findings}

Qualitative researchers do not approach research with a particular hypothesis to be proven or disproven, but rather examine complex topics in the context in which they occur (Merriam, 2009). Most qualitative research projects attempt to understand the complexities of the situation under investigation rather than to provide a strict definition or interpretation of the construct in question (Bogdan \& Biklen, 2006). True to the qualitative paradigm, this study reports its findings as themes that emerged through careful analysis of the participants' own words rather than statistical results. Analysis of the data yielded six primary themes. The first three themes highlight teachers' assumptions. The fourth illuminates teachers' backgrounds, and the fifth and sixth pertain to pre-referral interventions and the discrepancy model.

\section{Assumption: Hard Work Overcomes Poverty}

All eleven of the teachers interviewed made comments that reflect a belief that hard work overcomes poverty. This idea infused many of the stories and explanations that the Gilligan teachers shared. A general education teacher who teaches middle school math and science stated: “There's a few kids that seem like they might be struggling, but they could do it if they wanted to. They don't do anything to make themselves better. They don't ask for help, they don't work, they don't pay attention, but they can do it because we've seen them do it before." The teachers' beliefs about student performance reflected our society's emphasis on the principle that hard work surmounts all obstacles. This philosophy supports the practice of "blaming the victim": When students in poverty fail, they must not be working hard enough.

This belief that hard work overcomes poverty does not take into account the myriad of circumstances that make hard work in school seem fruitless to many students in poverty. A conclusion that can be drawn from this finding is that there is a mismatch between what the teachers believe and what the students have experienced that may cause dissonance or lack of trust of which the teachers may not be aware. The belief that parents may not be working hard enough has implications for the teacher-parent relationship as well.

\section{Assumption: Schools Can Fix the Poverty Problem}

More than half the teachers ( 7 out of 11) made comments supporting the belief that schools can and/or should "fix the poverty problem." While it is certainly more convenient to place the responsibility for success on students and parents, Gilligan teachers felt a strong obligation to their students and attempted to take responsibility for meeting their needs, both academic and personal. The middle school special education teacher provided numerous examples of how she, in conjunction with the school and the community, helped students meet some of their basic needs such as food and clothing:

We've got a supportive community here, so I've got a cupboard full of clothes. If someone needs clothes, if somebody needs shoes, if somebody needs $t$-shirts, we can take care of our own. I've got people that bring coats in for kids. A couple of times a year I'll get a call from someone in the community or an organization asking if there's anyone who needs something. We help kids out with eyeglasses and that kind of thing. We've got working poor families who really struggle if one of the kids breaks their glasses. I always have enough money in my budget to meet basic needs if we have to. I always have peanut butter and things here for snack if I have hungry kids.

Additional teachers talked about inviting students to eat lunch in their classrooms, spending time with students after school to assist with academics, and even volunteering to run supervised study sessions on Saturdays.

Although literature supports the assertion that "fixing the poverty problem" is beyond the scope of what schools and teachers can achieve (Gibboney, 2008; Rothstein, 2008), teachers expressed a fervent desire to help their students "overcome" poverty. It is interesting to note that the most obvious statements supporting the belief that schools can and should fix the poverty problem came from special education professionals.

Because teachers expressed the belief that they can make a meaningful contribution to "fixing the poverty problem," it could be concluded that teachers take responsibility for their students' learning and well-being even when there is evidence that students in poverty do not have access to the same advantages as their middle class peers. Another conclusion that can be drawn from this finding is that teachers are not seeking solutions outside their own innovation and hard work. In other words, they do not question the larger socioeconomic structure that has placed the families at Gilligan in poverty. Acknowledging the role of the economic structure could lead teachers to advocate for their students on an economic level, not just an academic level. Equally important, teachers 
could provide students with the knowledge they need to advocate for themselves.

\section{Assumption: "It's not that bad here}

Many of the Gilligan teachers (7 out of 11) expressed a conviction that supported the idea that "It's not that bad here." Although Gilligan has a high poverty rate and students are dealing with issues that their middle class peers in neighboring school districts do not need to consider, some teachers minimized the impact of poverty by citing other positive attributes of the Gilligan school district and community. Contrary to what the statistics tell us about Gilligan, the high school science teacher's comments reflected a belief that all schools have their problems and Gilligan is really no different than any other school district:

I don't think teaching here is any different than teaching anywhere else. Like every job, you've got different headaches. Teaching in a poor, rural school is like teaching anywhere else. You have the same number of headaches, just different ones. Instead of worrying about keeping up with the curriculum and what other teachers are doing, you're worried about whether the kid is going to get supper and if they're off the streets at night... I talk to a lot of teachers in a lot of other schools and I don't think [Gilligan] is any worse or any better than anywhere else.

We're just average.

As a result of their belief that "It's not that bad here," teachers are less likely to question the conditions in which their students live. They are also less likely to look beyond the immediate situation and examine the larger social implications and advocate for their students or their school when it comes to accessing resources or making systemic changes. If it is not that bad in Gilligan, why would anyone need to do anything to fight for substantial change?

\section{Teachers Come from Middle Class Backgrounds.}

Another theme that persistently surfaced throughout the data was the mismatch between the social class lenses of the teachers (which were typically middle class) and the social class experiences of the students they were attempting to serve. A vast majority of the teachers (10 out of 11 [90.9\%]) reported that their own social class background was middle class and all of the teachers (11 out of 11 [100\%]) made comments that support middle class values and beliefs. This difference in socioeconomic experiences contributed to the beliefs revealed in findings one through three. The middle class lens that most educators bring to the school setting significantly impacts their interpretation of the situation and how to deal with it. This is a theme that has persisted across settings and can be explained through Lott's (2002) theory of cognitive and behavioral distancing. Lott contends that middleclass people tend to respond to issues about poverty with ignorance, because they are largely isolated from and do not personally know poor people. A comment from the high school special education teacher highlighted this phenomenon.

A kid will give excuses for everything. Why his

family doesn't have money, why he is failing in school, why he did not get his homework done.

There is always an excuse. I talk to him and his response is you don't know how I live, you don't understand.

Ten of the 11 teachers interviewed self-reported growing up in a middle class household. Many of their comments reflected a mismatch between their own backgrounds and that of their students. The mismatch between the teachers' socioeconomic backgrounds and the lived experiences of their students is not unusual. In most high-poverty schools, students are taught by teachers whose backgrounds are dissimilar to their own. The majority of teachers in American schools are white, middle-class females (Diffily and Perkins, 2002; Olmeda, 1997). The increasingly diverse population of students in the schools, including in the area of socioeconomic status, has amplified the difference between the backgrounds of most teachers and the students for whom they are responsible (Zeichner, 2003).

A conclusion that can be drawn from this finding is that unexamined differences in social class experiences may lead to misunderstandings about expectations. Students are affected by this mismatch because teachers do not have adequate insight about how poverty influences life opportunities. This lack of understanding leads teachers to blame students and hold them accountable for their own success or failure rather than providing them with the support and advocacy that they need.

\section{Pre-referral Interventions were Minimal}

All of the five general education teachers interviewed expressed the view that at the pre-referral stage "we just have to show that we tried." The general education teachers reported trying prereferral interventions that were well-intentioned but did not provide struggling students with more intensive instruction. They reported interventions such as preferential seating, after school assistance, and extended time on tests and quizzes. The special 
education teachers' statements corroborated this finding, reporting that their general education colleagues tried minimal interventions prior to submitting a referral. According to one elementary special education teacher:

I don't think a lot of things have been tried before teachers refer students. I think some things have been tried in some cases, but not always. Mostly just giving them a little more attention, checking in with the student on an individual basis to make sure they're getting it.

As reflected in this statement, the pre-referral interventions that were being implemented would certainly not meet the Response to Intervention (RTI) criteria for intense, research-based interventions. The other elementary special education teacher shared a similar sentiment:

And other times I think for some teachers it's easier to give up and say, "Oh, there must be something wrong." They pass the buck rather than make an honest effort to give the student what they need.

This finding might indicate that teachers are interested in getting students specialized help at the earliest point possible and that they believe that more intensive pre-referral interventions simply delay the acquisition of services. This finding could be used to support the conclusion that the teachers in this highpoverty setting do not see the value in attempting more intensive interventions for struggling students. Perhaps the poverty factor influences the expectation that students who struggle are not going to succeed in the general education classroom. Another possible conclusion is that teachers have not been provided with the knowledge and skills to implement the more intensive interventions that are characteristic of the RTI model.

\section{IQ-Achievement Discrepancy Model is still in Place}

A majority of the special education teachers interviewed (5 out of 6) described an IQ-

Achievement Discrepancy model for determining LD eligibility and reported that the discussion about exclusionary factors was either not occurring or was occurring without parent knowledge. Finding Six is based on data that reflect how teachers talked about the identification process. The researcher asked the general education teachers questions such as, "How do you go about determining if a child should be referred for special education?" and "How has special education referral changed since the beginning of your career?" The special education teachers were asked questions such as, "What types of data do you use to determine eligibility for LD?" The terms "IQ-
Achievement discrepancy model" and "RTI" were purposefully avoided and more open-ended questions were asked to see what the teachers would say without being directly prompted with language that might affect their responses. Because of this line of questioning, many teachers mentioned neither the IQAchievement discrepancy model nor RTI.

Finding Six was supported by teachers' statements relative to the decision to refer, the appropriateness of the referrals made, and the actual identification process. The teachers also made limited reference to RTI and their responses indicated that they had limited knowledge of RTI, with only one participant reporting the RTI had been implemented at Gilligan. None of the other participants made comments in support of this statement.

Evidence indicated that legal mandates outlined in the Individuals with Disabilities Education Act (IDEA) 2004 and in state law were not being followed. For example, parents were not truly being included as decision-making partners but were invited to a meeting where the decisions had essentially already been made. The lack of RTI implementation and the avoidance of the discussion regarding exclusionary factors were also noteworthy. One conclusion that can be drawn from this finding is that the teachers are student-centered rather than system-motivated and do not see the value in following the letter of the law. In other words, if they can get assistance for a struggling student by disregarding certain aspects of special education law, then they will do so. Another potential conclusion is that the teachers do not have adequate training in LD identification, particularly in light of IDEA 2004. Even the youngest teachers took their coursework in special education prior to the widespread implementation of RTI. Many of the teachers have not taken special education coursework for many years, meaning RTI was not even a component of the teacher education curriculum. This study found no evidence of RTI professional development provided for the Gilligan teachers and data indicated that school and District administrators had stated that Gilligan should "hold off" on RTI implementation for now.

Throughout the study, the participants' own words were used to support the findings. Teachers are in the unique position of seeing what happens every day in the classroom and they also have firsthand experience in how the implementation of policy actually occurs. Using the teachers' voices to develop the themes provided a deep description of the situation under investigation and also added authenticity to the findings. In summary, the findings suggest that the teacher's middle class backgrounds 
and attitudes about poverty significantly impact their ability to understand the context from which their students come. In addition, there is a mismatch between the teachers' perceptions of the LD identification process and what is mandated by law.

\section{Recommendations}

After careful examination of the findings, the following recommended actions are submitted for consideration by teachers, school administrators, and education scholars:

Action 1: Institutions of higher education and school district administrators should provide educational activities to both future and current educators that challenge stereotypical beliefs about people living in poverty.

The stereotypical beliefs that teachers hold about poverty are highly evident in the findings. It is likely that teachers do not realize that they are placing blame on students and parents. Taking a closer look at the facts about poverty and challenging taken-forgranted assumptions about the poor is critical to the formation of positive relationships and finding ways to help all students be successful. "Mythology cannot, in the long run, inspire better instruction" (Rothstein, 2008). Once the myths have been uncovered and analyzed, educators will be in better position to focus on solutions rather than blame. In order to effect meaningful change, educators need to cease the blaming and focus efforts on solutions that improve instruction and relationship-building.

Teachers are negatively impacted when society places blame on high-poverty schools for their failure to address the multitude of issues with which they are presented. Blaming schools for circumstances they cannot change does not solve the problem. Education scholars have an obligation to make stakeholders aware of the challenges for which schools should and should not be held accountable.

Action 2: Policy makers should consider socioeconomic reform in discussions about school improvement.

Improving educational outcomes for students in high-poverty schools can only be accomplished with a combination of school-based reforms and changes that narrow the vast socioeconomic inequalities in the United States. Schools alone cannot fix the poverty problem. Instead of taking the blame for the low achievement in high-poverty schools, educators should consider joining forces with advocates of social and economic reform to improve the conditions from which children come to school (Rothstein, 2008). Social and economic reforms should be implemented together to create an environment in which the most effective teaching can take place.

Action 3: School administrators should support teachers in their efforts to meet the needs of all students in their classrooms.

Teachers need to differentiate their instruction to cater to a wide range of student needs and learning styles. This is especially important in high-poverty schools. Meeting the needs of all students is not an easy task and teachers need assistance in this endeavor. Teachers require support to develop the skills related to differentiation. They also deserve recognition for their efforts in this area. It is important to celebrate successes, and it is also essential to take a critical look at teaching practices. Instead of assuming that student failure is due to a problem within the child, educators need to consider that they may not be teaching him or her correctly and seek strategies that are more effective. RTI provides the tools for general education teachers to meet this goal.

Action 4: School administrators should facilitate the implementation of assessment methods that are designed so that students receive the assistance they need as early as possible.

RTI also provides a framework for meeting this goal. Unfortunately, many small rural schools like Gilligan have not received the training or resources to implement RTI and, according to the teachers interviewed for this study, have even been discouraged from examining RTI as a viable option until a later date. RTI is an improvement over the IQ-Achievement discrepancy model because it is not a "wait to fail" approach. Struggling learners begin receiving interventions at the earliest sign of difficulty. Rural students need access to the same high-quality programming options that are available in middle class urban and suburban settings.

\section{Action 5: Researchers should continue to explore} poverty issues in rural contexts.

As indicated in the review of literature, rural schools are underrepresented in the scholarly literature. Although rural children are more likely to be poor than either non-rural or children in the United States overall (Jensen, 2006), the literature revealed little about the rural poor (Books, 1997). Although this study contributes to the scarcity of research 
regarding rural poverty and its effects on the education of children, it is only a start. There is much work to be done related to high-poverty, rural schools.

\section{Conclusions}

The research findings suggest that the teachers in the Gilligan School District ressemble many teachers across the country. They care about their students and they work hard to help their students succeed. Many positive student-centered practices are employed at Gilligan. In relation to poverty issues, the teachers' reactions range from sympathy and nurturing to placing blame on the parents or the students themselves.

As far as the identification of learning disabilities is concerned, the teachers at Gilligan describe practices that reflect good intentions, such as implementing traditional pre-referral interventions. As the findings reveal, however, practice far from followed the letter of the law. Professional development opportunities for current teachers and appropriate educational opportunities for pre-service teachers have the potential to improve the LD identification process in all schools. Additional research on high-poverty rural schools is needed in order to develop teachers' knowledge and skills in this critical area.

\section{References}

Bateman, B. (2005). The play's the thing. Learning Disabilities Quarterly, 28(2), 93-95.

Bocian, K. M., Beebe, M. E., McMillan D., \& Gresham, F. M. (1999). Competing paradigms in learning disabilities classification by schools and the variations in the meaning of discrepant achievement. Learning Disabilities Research \& Practice, 14(1), 1-14.

Bogdan, R., \& Biklen, S. K. (2006). Qualitative research for education: An introduction to theories and methods ( $5^{\text {th }}$ ed.). Needham Heights, MA: Allyn \& Bacon.

Books, S. (1997). The other poor: Rural poverty and education. Educational Foundations, 11(1), 7385.

Diffily, D., \& Perkins, H. (2002). Preparing to teach in urban schools: Advice from urban teachers. Teacher Education and Practice: The Journal of the Texas Association of Colleges for Teacher Education, 15(1-2), 57-73.

Dombrowski, S. C., Kamphaus, R. W., \& Reynolds, C. R. (2004). After the demise of the discrepancy: Proposed learning disabilities diagnostic criteria. Professional Psychology: Research and Practice, 35(4), 364-372.

Fletcher, T., \& Navarrete, L. (2003). Learning disabilities or difference: A critical look at the issues associated with the misidentification and placement of Hispanic students in special education programs. Rural Special Education Quarterly, 22(4), 37-46.

Fuchs, D. M., Mock, D., Morgan, P. L., \& Young, C. L. (2003). Responsiveness-to-intervention:
Definitions, evidence, and implications for the learning disabilities construct. Learning

Disabilities: Resource \& Practice, 18(3), 157-171.

Fuchs, L.S., \& Fuchs, D. (2006). Implementing responsiveness to intervention to identify learning disabilities. Perspectives, 32(1), 39-43.

Gibboney, R.A. (2008, September). Why an undemocratic capitalism has brought public education to its knees: A manifesto. Phi Delta Kappan, 90(1), 21-31.

Harris, J. D., Gray, B. A., Davis, J. E., Zaremba, E. T., \& Argulewicz, E. N. (1997). The exclusionary clause and the disadvantaged: Do we try to comply with the law? Journal of Learning Disabilities, 21(9), 581-583.

Jensen, L. (2006). At the razor's edge: Building hope for America's rural poor [Electronic Version]. Rural Sociology's Quarterly Publication, 1(1).

Lerner, J.W., \& Johns, B. (2009). Learning disabilities and related mild disabilities: Characteristics, teaching strategies, and new directions. Boston, MA: Houghton Mifflin Harcourt Publishing Company.

Lott, B. (2002). Cognitive and behavioral distancing from the poor [Electronic version]. American Psychologist, 57(2), 100-110.

Merriam, S.B. (2009). Qualitative research: A guide to design and implementation. Jossey-Bass: San Francisco.

O'Hare, W.P. (2009). The forgotten fifth: Child poverty in rural America. Durham, NH: Carsey Institute. 
Olmeda, I.M. (1997). Challenging old assumptions: Preparing teachers for inner city schools. Teacher and Teacher Education, 13(3), 245-58.

Rothstein, R. (2008, April). Whose problem is poverty? Educational Leadership, 65(7), 8-13.

Shepard, L. (1983). The role of measurement in educational policy: Lessons from the identification of learning disabilities. Educational Measurement: Issues and Practice, 29(7), 4-8.

Torgesen, J. K. (2002). The prevention of reading difficulties. Journal of School Psychology, 40(1), 7-26.

Turnbull, A., Turnbull, R., \& Wehmeyer, M. L. (2007). Exceptional lives: Special education in today's schools. Upper Saddle River, NJ: Pearson Education.

U.S. Department of Education (2004). Individuals with Disabilities Education Improvement Act of 2004, Pub. L. No. 108-446 § 1400 et seq.

Weintraub, F. (2005). The evolution of LD policy and future challenges. Learning Disabilities Quarterly, 28(2), 97-99.

Zeichner, K. M. (2003). The adequacies and inadequacies of three current strategies to recruit, prepare, and retain the best teachers for all students. Teachers College Record, 105(3), 490519.

\section{About the Author:}

Dr. Renee Chandler is an Associate Professor in the School of Education at the University of Wisconsin-Stout. Her background includes teaching students in general and special education in the public schools and teaching in higher education. Dr. Chandler's research interests include assessment, Universal Design for Learning (UDL), highpoverty schools, and rural education. 